\title{
Clinical significance of serum tumor markers for gastric cancer: a systematic review of literature by the Task Force of the Japanese Gastric Cancer Association
}

\author{
Hideaki Shimada $\cdot$ Tamaki Noie $\cdot$ Manabu Ohashi $\cdot$ \\ Koji Oba $\cdot$ Yutaka Takahashi
}

Received: 25 December 2012/ Accepted: 24 March 2013/Published online: 10 April 2013

(c) The International Gastric Cancer Association and The Japanese Gastric Cancer Association 2013

\begin{abstract}
The aim of this review was to evaluate the clinical significance of serum tumor markers, particularly CEA, CA19-9, and CA72-4, in patients with gastric cancer. A systematic literature search was performed using PubMed/MEDLINE with the keywords "gastric cancer" and "tumor marker," to select 4,925 relevant reports published before the end of November 2012. A total of 187 publications contained data for CEA and CA19-9, and 19 publications contained data related to all three tumor markers. The positive rates were $21.1 \%$ for CEA, $27.8 \%$ for CA199 , and $30.0 \%$ for CA72-4. These three markers were significantly associated with tumor stage and patient survival. Serum markers are not useful for early cancer, but they are
\end{abstract}

\section{H. Shimada $(\varangle)$}

Department of Surgery, School of Medicine, Toho University, 6-11-1 Omori-Nishi, Ota-ku, Tokyo 143-8541, Japan

e-mail: hideaki.shimada@med.toho-u.ac.jp

\section{H. Shimada}

Japanese Gastric Cancer Association Task Force for Research Promotion, Tokyo, Japan

T. Noie

Department of Surgery, Kanto Medical Center NTT East,

Tokyo 141-8625, Japan

\section{Ohashi}

Department of Surgery, Tokyo Metropolitan Komagome Hospital, Tokyo 113-8677, Japan

\section{K. Oba}

Translational Research and Clinical Trial Center, Hokkaido University Hospital, Hokkaido University,

Hokkaido 060-8648, Japan

Y. Takahashi

Cancer Chemotherapy, KAKEN Hospital, International

University of Health and Welfare, Ichikawa 272-0827, Japan useful for detecting recurrence and distant metastasis, predicting patient survival, and monitoring after surgery. Tumor marker monitoring may be useful for patients after surgery because the positive conversion of tumor markers usually occurs 2-3 months before imaging abnormalities. Among other tumor markers, alpha-fetoprotein (AFP) is useful for detecting and predicting liver metastases. Moreover, CA125 and sialyl Tn antigens (STN) are useful for detecting peritoneal metastases. Although no prospective trial has yet been completed to evaluate the clinical significance of these serum markers, this literature survey suggests that combinations of CEA, CA19-9, and CA72-4 are the most effective ways for staging before surgery or chemotherapy. In particular, monitoring tumor markers that were elevated before surgery or chemotherapy could be useful for detection of recurrence or evaluation of the response.

Keywords CA19-9 - CA72-4 - CEA - Gastric cancer · Serum tumor marker $\cdot$ Systematic review

\section{Introduction}

The Japanese Public Health Insurance System covers the costs of monitoring patients with gastric cancer using serum tumor markers. Nine types of serum markers are officially certified for use in disease monitoring: carcinoembryonic antigen (CEA) in the sialyl Lewis A group; CA19-9 and CA50 in the sialyl Lewis Tn group; STN and CA72-4 in the mucin antigen group; and CA125, alphafetoprotein (AFP), IAP, and TPA. Many studies have demonstrated the clinical significance of each marker; however, appropriate indications for serum tumor marker monitoring remain unclear. The serum levels of CEA, 
CA19-9, and CA72-4 may be elevated in patients with gastric cancer at various stages [1]. AFP [2], CA125 [3], and STN [4] can be used to detect liver metastases and/or peritoneal metastases. However, low rates of sensitivity and specificity prevent the use of any of these serum markers in early diagnosis. The National Comprehensive Cancer Network guidelines (http://www.nccn.org) do not recommend serum marker testing for preoperative evaluation and staging of gastric cancer.

In this context, the Task Force of the Japanese Gastric Cancer Association for Research Promotion (directed by Dr. Motoki Ninomiya) planned to reevaluate the clinical impact of serum tumor markers in a systematic review of previous publications, focusing mainly on CEA, CA19-9, and CA72-4. The clinical significance of the three other serum markers, AFP, CA125, and STN, was also addressed. Prospective clinical studies can be planned based on the results of this systematic review to elucidate the clinical utility of serum tumor markers.

\section{Manuscript selection}

A computer-aided search of the PubMed website (http://www.ncbi.nlm.nih.gov/sites/entrez) was conducted to retrieve relevant articles on serum tumor markers used for gastric cancer. The keywords "gastric cancer" and "tumor marker" and the serum markers CEA, CA19-9, CA72-4, AFP, CA125, STN, TPA, and IAP were used to search for relevant articles published before the end of November 2012 (Table 1). Studies investigating the clinicopathological impact of preoperative serum tumor markers used for assessing patients with gastric cancer were selected. Furthermore, case reports, review article, non-English articles, articles that included less than 30 patients, and articles that addressed cancers other than gastric cancer were excluded. Four researchers (H.S., T.N., M.O., and Y.T.) reviewed all the articles, and after applying the inclusion and exclusion criteria arrived at a consensus about articles to be selected at a working meeting. A total of 657 articles were selected from the PubMed database using the keyword "CEA." A total of 46 articles were selected as references for the present review article to evaluate the positive rates for CEA $(n=8,104)$, CA19-9 $(n=5,300)$, and CA72-4 ( $n=2,774)$ [4-49]. In this review, the number of positive patients reported as positive, based on the definition in each original paper, was used to calculate the combined positive rates of patients with early/advanced gastric cancer. The positive rates for each marker at each stage were calculated. Among these 46 articles, 19 articles $[1,9,12,15,19,20,22,26,27,31,32,34-37,39,42,43$, 50] analyzed all three markers, CEA, CA19-9, and CA72-4, which included 2,774 patients (Table 2). Four discussion
Table 1 Key words with "gastric cancer and tumor marker" and number of publications from PUBMED search

\begin{tabular}{ll}
\hline Key words & $\begin{array}{l}\text { Number of } \\
\text { publications }\end{array}$ \\
\hline CEA & 657 \\
CA19-9 & 281 \\
CEA + CA19-9 & 187 \\
AFP & 179 \\
CA125 & 44 \\
CEA + AFP & 42 \\
CEA + CA125 & 28 \\
CA72-4 & 26 \\
STN & 26 \\
CEA + CA72-4 & 25 \\
CEA + CA19-9 + CA72-4 & 24 \\
IAP & 21 \\
CA50 & 7 \\
\hline
\end{tabular}

points were evaluated for CEA, CA19-9, and CA72-4 from selected articles as follows: (1) positive rates, (2) clinicopathological significance, (3) prognostic impact, and (4) clinical impact during follow-up after surgery and/or during chemotherapy. Finally, we selected 10 other publications that focused only on AFP [51-54], CA125 [3, 55-57], and STN $[58,59]$ in patients with gastric cancer to analyze the clinical significance of these three serum markers.

\section{Positive rates for each serum marker according to the TNM stages}

In the initial 46 articles, the overall positive rates for each marker were as follows: $24.0 \%(1,945 / 8,104)$ for CEA, $27.0 \%(1,431 / 5,300)$ for CA19-9, and $29.9 \%(829 / 2,774)$ for CA72-4. The positive rates for CEA during each stage were as follows: stage I $=13.7 \%$, stage II $=23.0 \%$, stage III $=25.6 \%$, and stage IV $=39.5 \%$. The positive rates for CA19-9 during each stage were as follows: stage $\mathrm{I}=9.0 \%$, stage $\quad$ II $=19.9 \%$, stage $\quad$ III $=32.2 \%$, and stage $\mathrm{IV}=44.7 \%$. The positive rates for CA72-4 during each stage were as follows: stage I $=12.0 \%$, stage $\mathrm{II}=15.6 \%$, stage III $=36.7 \%$, and stage IV $=49.6 \%$ (Fig. 1 ).

The 19 manuscripts that evaluated all three markers in the same group of patients $(n=2,774)$ showed a similar trend as shown in Fig. 1 (Table 2). The positive rate for CA72-4 was the highest among the three markers (Fig. 2). Among these 19 articles, 12 articles indicated that the positive rate for CA72-4 was the highest among the three serum markers (Table 2). The combination with the highest positive rate was CA19-9 and CA72-4 [15, 50]. Because the average frequency of these three markers was approximately $10 \%$ at stage I $(\mathrm{CEA}=13.7 \%$, CA19- 
Table 2 A total of 19 publications analyzed all three serum markers CEA, CA19-9, and CA72-4 in patients with gastric cancer

\begin{tabular}{|c|c|c|c|c|c|c|c|}
\hline Reference & Author & Journal & Year & $\begin{array}{l}\text { Number } \\
\text { of patients }\end{array}$ & CEA $(\%)$ & CA19-9 (\%) & CA72-4 (\%) \\
\hline 9 & Guadagni F & Cancer Res & 1992 & 94 & 20 & 32 & 43 \\
\hline 12 & Guadagni F & Anticancer Res & 1993 & 161 & 42 & 34 & 22 \\
\hline 15 & Filella X & Acta Oncol & 1994 & 79 & 33 & 46 & 47 \\
\hline 19 & Fernandez-Fernandez L & Int Surg & 1996 & 167 & 21 & 26 & 60 \\
\hline 20 & Spila A & Anticancer Res & 1996 & 242 & 22 & 33 & 41 \\
\hline 22 & Pectasides D & Am J Clin Oncol & 1997 & 62 & 49 & 65 & 70 \\
\hline 26 & Tocchi A & J Cancer Res Clin Oncol & 1998 & 59 & 58 & 39 & 19 \\
\hline 28 & Marrelli D & Oncology & 1999 & 254 & 21 & 35 & 28 \\
\hline 31 & Marrelli D & J Surg Oncol & 2001 & 167 & 16 & 34 & 20 \\
\hline 32 & Marrelli D & Am J Surg & 2001 & 133 & 16 & 35 & 20 \\
\hline 34 & Gaspar MJ & Tumour Biol & 2001 & 82 & 16 & 33 & 34 \\
\hline 35 & Mattar R & Rev Hosp Clin Fac Med Sao Paulo & 2002 & 44 & 25 & 25 & 48 \\
\hline 36 & Lai IR & Hepatogastroenterology & 2002 & 195 & 32 & 16 & 16 \\
\hline 37 & Aloe $\mathrm{S}$ & Int J Biol Markers & 2003 & 166 & 23 & 25 & 37 \\
\hline 39 & Louhimo J & Int J Cancer & 2004 & 146 & 18 & 31 & 34 \\
\hline 42 & Goral V & Hepatogastroenterology & 2007 & 47 & 30.5 & 30 & 46.8 \\
\hline 43 & Ucar E & Adv Ther & 2008 & 95 & 24.2 & 41 & 32.6 \\
\hline 1 & Kim DH & J Surg Oncol. & 2011 & 312 & 1 & 1 & 5 \\
\hline 1 & Kim DH & J Surg Oncol. & 2011 & 167 & 5 & 13 & 15 \\
\hline 50 & Emoto $\mathrm{S}$ & Gastric Cancer & 2012 & 102 & 19 & 37 & 44.9 \\
\hline
\end{tabular}

Reference [1] presented data of "early" and "advanced" tumors separately

Positive rates are shown as \%

Fig. 1 Positive rate of serum tumor markers in gastric cancer according to stage

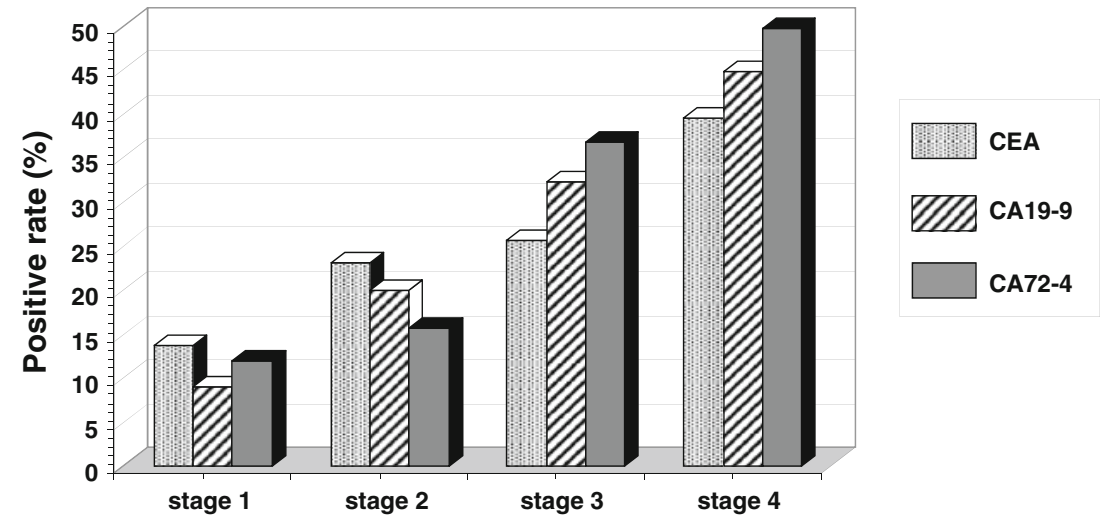

$9=9.0 \%$, and CA72-4 $=12.0 \%$, they may not be useful for early cancer screening. Although the positive rates for CEA, CA19-9, and CA72-4 were similar in detecting major tumors, CA72-4 had the highest positive rate in patients with nodal involvement or serosal invasion. Therefore, CA72-4 was the most useful marker for detecting advanced gastric cancer [34, 39, 42, 43].

A recent meta-analysis of Chinese studies also showed that CA72-4 was the best of these three serum markers [60]. The accumulated accuracy rate of CA72-4 was $77 \%$, which was better than others. CA72-4 was the most highly correlated serum tumor biomarker for gastric cancer in the
Chinese population. A combination of CA72-4 + CEA + CA19-9 considerably improved the positive rate without impairing the specificity.

\section{Association of elevated serum markers with clinicopathological factors}

\section{CEA}

The overall positive rates for CEA were 16-68\%. CEA was strongly associated with the $\mathrm{T}$ factor [29, 30, 33, 37], 


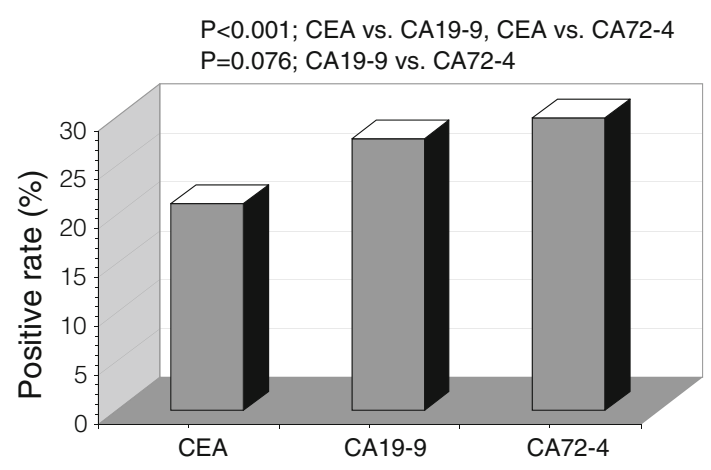

Fig. 2 Positive rate of each serum tumor marker in gastric cancer: In 19 articles, a total of 2,774 patients showed positive rates of all three serum markers

$\mathrm{N}$ factor $[18,24,27,29,30], \mathrm{M}$ factor $[5,6,11,24,27,33$, 43], and stage [18, 27, 29, 39, 40, 45, 48]. Ikeda et al. [11] analyzed 68 patients with stage IV gastric cancer using multivariate analysis and concluded that an elevated CEA level was an independent risk factor for predicting liver metastases. A few reports have shown a significant association between elevated CEA and peritoneal metastases $[18,34]$. Although several reports showed that elevated CEA was significantly associated with differentiated tumor types [7, 10, 48, 61], a few reports indicated an association with poorly differentiated types of tumors [29]. Maehara et al. analyzed the CEA levels in 221 patients with welldifferentiated gastric cancer. The CEA-positive patients had larger tumors, greater serosal invasion, more frequent lymphatic and vascular involvement, less expansive tumor growth, and higher rates of lymph node and hepatic metastases than CEA-negative patients [17].

\section{CA19-9}

The overall positive rates for CA19-9 were reported as 14-68 \%. Elevated CA19-9 was associated with tumor depth [30, 37], nodal involvement [18, 34, 40, 43, 47, 48], peritoneal metastases $[18,34,43]$, and stage $[18,30,34$, $43,47]$. Of these various clinicopathological factors, CA19-9 was frequently reported to be associated with nodal involvement. The positive predictive value for nodal involvement was reported to be $78-96 \%$ [18, 43, 47]. The positive predictive value for peritoneal metastases was reported to be $27 \%$ [18] or $24 \%$ [17]. Kodera et al. [18] reported that elevated CA19-9 levels were strongly associated with liver metastases.

\section{CA72-4}

The overall positive rates for CA72-4 were reported to be 16-70\%, which were generally higher than CEA and CA19-9 [1, 12, 37, 39, 42, 50]. Elevated CA72-4 was associated with tumor depth [28, 37, 43], nodal involvement $[10,12,20,24,28,34,37,42,43]$, peritoneal metastases [10, 24, 34, 43], distant metastases [34, 43], and stage $[9,20,28,34,35,39,42,43]$. Ucar et al. [43] reported that 9 of 11 patients ( $82 \%$ ) with liver metastases were positive for CA72-4. Because the positive rate for CA72-4 in patients with poorly differentiated adenocarcinoma was significantly higher than that for CEA (36 vs. $8 \%$ ), the overall positive rate for CA72-4 was higher than that for CEA [25]. In patients with Bormann type 2, 3, and 4, the positive rates for CA72-4 were higher than that for CEA. In particular, the positive rate for CA72-4 was significantly higher than that for CEA in patients with Bormann type 4 (67 vs. $11 \%$ ) [10]. The positive rate for CA72-4 was higher than that for CEA in stage III or IV patients. In particular, the positive rate for CA72-4 was significantly higher than that for CEA in patients with peritoneal metastases (69 vs. $23 \%$ ) [10].

\section{Association of elevated serum markers with recurrence and patient survival}

Because elevated serum markers were generally associated with tumor progression, most previous reports concluded that preoperative elevated serum markers were significantly associated with poor long-term patient survival. The prognostic value of preoperative CEA was confirmed by univariate analysis $[18,27,28,30,34,43,44]$ and multivariate analysis using TNM factors [13, 14, 23, 25, 26, 62]. The prognostic value of preoperative CA19-9 was also confirmed by univariate analysis $[25,27,28,30,31,34,39$, $40,43]$ and multivariate analysis using TNM factors [18, 26, 29, 44, 63]. The prognostic value of preoperative CA72-4 was also confirmed by univariate analysis [23, 24] and multivariate analysis using TNM factors $[33,39,43$, 63]. Although none of the three markers was associated with peritoneal recurrences, preoperative positivity for CEA, CA19-9, or CA72-4 was an independent risk factor for hematogenous recurrences of gastric carcinoma, and this point should be considered when selecting adjuvant chemotherapy after surgery for gastric cancer [1, 24, 32, 37]. Among these three markers, preoperative elevated CA72-4 was an independent risk factor for reduced patient survival in a multivariate analysis when co-analyzed with CEA and CA19-9 [63].

Takahashi et al. [38] reported that the CEA levels and/or CA19-9 levels increased for the first time at recurrence (54.7 and $40.0 \%$, respectively). Sensitivities for CEA and CA19-9, and combinations of the two markers, for indicating recurrence were $65.8,55.0$, and $85.0 \%$ [38]. More than $90 \%$ of patients with elevated preoperative levels of CEA had increased CEA levels again at the time of 
recurrence. Similarly, the CA19-9 level increased again at recurrence in more than $90 \%$ of patients with high preoperative levels of this marker [38]. Kim et al. confirmed these findings based on follow-up data from 1,117 patients. They concluded that the postoperative elevation of CEA and/or CA72-4 were both independent risk factors for recurrence [1]. Liu et al. [64] also reported that CA72-4 was the highest in sensitivity (35\%) and that the combined triple markers had $62 \%$ sensitivity in the diagnosis of recurrence. They also reported false-positive rates of CEA, CA19-9, CA72-4, and the triple markers were 5.6, 7.0, 9.9, and $18.3 \%$, respectively [64]. Choi et al. [65] reported that the majority $(90 \%)$ of cases with recurrence to the liver had an elevated CEA, whereas an elevated CA 19-9 postoperatively was more predictive of a peritoneal recurrence (78.9 \%). CA19-9 may be particularly useful as a marker of peritoneal recurrence, whereas CEA could be a useful marker for recurrence in the liver [65].

Therefore, the patients should have a set of markers evaluated once preoperatively. Measurement during the postoperative follow-up would then be particularly important for those who had elevated preoperative values, although one cannot deny the relevance of measuring tumor markers among patients who did not have an elevated preoperative value.

\section{Doubling time and lead time of elevated serum markers}

The reported doubling time estimate, based on the serum level of CEA, agreed with the actual tumor doubling time in 112 previously untreated patients with recurrent gastric cancers [66]. The CEA doubling time ranged from 12 to 105 days, with a mean of 37.5 days. The CEA doubling time was significantly shorter in patients with papillary adenocarcinoma compared with those with well- or moderately differentiated tubular adenocarcinoma. The doubling time was also significantly shorter in patients with liver metastasis than those with lymph node metastasis or peritoneal dissemination. There was also a significant correlation between the CEA doubling time and postoperative survival time of patients who received no chemotherapy.

The serum markers were frequently elevated several months before imaging abnormalities. Thus, the lead time before imaging abnormalities was reduced gradually because of improvements in imaging technology. In 1982, Tamada et al. [5] reported that the lead time for CEA was 8.3 months. Because of improvements in imaging modalities, recent studies (after 2000) reported a shorter mean lead time than that reported earlier (3-5 months for CEA and 2-5 months for CA19-9) [31, 38]. The preoperative seropositive group was more likely to have a longer lead time than the preoperative seronegative group. The lead times for recurrences in the liver, peritoneum, and lymph nodes were 1.2, 3.4, and 3.7 months, respectively, for CEA and 2.1, 1.0, and 3.6 months, respectively, for CA19-9. The lead time for CEA for liver recurrence was significantly shorter than those for peritoneum and lymph node metastases [38]. It was concluded that because the lead time depends on the imaging modalities and follow-up interval, a large-scale prospective study is required to clarify the best strategy for follow-up to improve overall patient survival.

\section{Clinical significance of serum marker monitoring during chemotherapy}

Yamao et al. [66] monitored changing patterns in CEA, CA19-9, and CA125 levels during systemic chemotherapy to determine the relationship between changes in the serum tumor marker levels and the response assessment in imaging studies throughout the treatment course. The sensitivity and negative predictive value of falling tumor marker levels after chemotherapy for a partial response in imaging was $100 \%$. On categorizing the patients as responders or nonresponders, a significant correlation was observed between the assessment of response by tumor markers and by imaging studies. The survival time of responders assessed by tumor markers was significantly longer than that of nonresponders [66]. Catalano et al. analyzed the CEA levels in 175 patients with advanced gastric cancer who received second-line chemotherapy. Univariate and multivariate analyses showed that elevated CEA levels $>50 \mathrm{ng} / \mathrm{ml}$ were significantly associated with poor overall survival. This analysis suggests that readily available clinical factors may help to select patients with advanced gastric cancer who may benefit from second-line chemotherapy [67].

Regarding elevated serum marker levels immediately after chemotherapy, Kim et al. [68] reported a transient increase in the CEA or CA19-9 levels despite the clinical benefits of chemotherapy in patients with metastatic or recurrent gastric cancer. CEA and CA 19-9 surges were defined as $>20 \%$ increases in these tumor marker levels from the baseline, followed by $>20 \%$ drop in subsequent levels compared with the baseline. Of 51 patients who were evaluated for CEA surges, nine $(18 \%)$ patients had CEA surges. The median time to the CEA peak and the duration of the CEA surge were 2.8 and 9.1 weeks, respectively. Of 40 patients who were evaluated for CA19-9 surges, 7 (18\%) had CA19-9 surges. The median time to the peak and the duration of the CA19-9 surge were 2.3 and 7.1 weeks, respectively. All patients with these surge phenomena received clinical benefits from chemotherapy. Although increases in serum tumor markers after chemotherapy were general indicators of tumor progression, an initial rise in the CEA or CA19-9 levels after the initiation 
Table 3 Clinical significance of serum tumor markers in gastric cancer

\begin{tabular}{llllllll}
\hline & T & N & M & P & Histology & Prognosis & Recurrence pattern \\
\hline CEA & Yes & Yes & Yes & No & Yes & Yes & Distant \\
CA19-9 & Yes & Yes & Yes & Yes & No & Yes & Distant \\
CA72-4 & Yes & Yes & Yes & Yes & No & Yes & Distant and/or peritoneal \\
AFP & NA & NA & Yes & NA & Yes & Yes & Liver \\
CA125 & NA & NA & NA & Yes & No & Yes & Peritoneal \\
STN & NA & NA & Yes & Yes & No & Yes & Peritoneal \\
\hline
\end{tabular}

$N A$ not enough evidence to evaluate clinical significance was available

of chemotherapy should not be an indicator of progressive disease in some cases [68].

\section{Other useful serum markers for gastric cancer: alpha- fetoprotein (AFP), CA125, and sialyl Tn antigens (STN)}

AFP-producing gastric cancers behave aggressively and have a high potential for metastasis to the liver [2, 52-54]. There was poorer differentiation, a higher incidence of lymph node metastasis, and more marked lymphatic and vascular invasion in the AFP-positive group than in the AFP-negative group [54].

The diagnostic ability of the serum CA125 was more reliable than other imaging modalities including computed tomography, ultrasonography, and the other serum tumor markers for peritoneal metastasis from gastric carcinoma [3]. The predictive values of the serum CA125 levels at a cutoff value of $35 \mathrm{U} / \mathrm{ml}$ resulted in a sensitivity of $39.4 \%$, a specificity of $95.7 \%$, and a diagnostic accuracy of $90.8 \%$. Hwang et al. [57] analyzed the utility of diagnostic imaging and CA125 levels in the sera of 768 patients with gastric cancer. The serum CA125 levels had high sensitivity $(38.6 \%)$, specificity $(98.4 \%)$, and diagnostic accuracy $(91.5 \%)$. Emoto et al. [50] also showed the sensitivities of CA125 for peritoneal metastasis at the initial diagnosis was $46 \%$. The CA125 level was significantly correlated with the degree of peritoneal dissemination and patient survival $[50,55,57]$.

Takahashi et al. $[4,58]$ evaluated the clinical significance of the serum STN level as a tumor marker in 350 patients with gastric cancer. Histologically, the tumors in the high STN group were deeply penetrating and the rates of lymphatic involvement, vascular involvement, and lymph node and hepatic metastases were higher. The 5 -year survival rate for patients in the high STN group was significantly less than that of patients in the low STN group (44.8 vs. $75.1 \%, P<0.05$ ). Nakagoe et al. [59] confirmed similar conclusions that high serum STN was an independent factor that predicted liver metastasis and a worse outcome in gastric cancer patients.
Because these three markers could classify advanced gastric cancer into a specific category, measurement during the postoperative follow-up would be particularly important for those who had elevated preoperative values.

In conclusion, this systematic review evaluated 657 publications related to serum tumor markers in patients with gastric cancer (Table 3). Although no prospective trial has yet been completed to evaluate the clinical significance of these serum markers, this literature survey suggests that combinations of CEA, CA19-9, and CA72-4 are the most effective ways for staging before surgery and chemotherapy. Monitoring those positive markers after treatment should be important. AFP is useful for detecting and predicting liver metastases. CA125 and STN are useful for detecting peritoneal metastases. Any of these serum markers may be a risk factor for poor patient survival. Final conclusions about the clinical utility of these serum markers for patients with gastric cancer during treatment should be clarified in a phase III prospective randomized trial for certain anticancer agents or radical surgery.

\section{References}

1. Kim DH, Oh SJ, Oh CA, Choi MG, Noh JH, Sohn TS, et al. The relationships between perioperative CEA, CA 19-9, and CA 72-4 and recurrence in gastric cancer patients after curative radical gastrectomy. J Surg Oncol. 2011;104:585-91.

2. Ishigami S, Natsugoe S, Nakashima H, Tokuda K, Nakajo A, Okumura $\mathrm{H}$, et al. Biological aggressiveness of alpha-fetoprotein (AFP)-positive gastric cancer. Hepatogastroenterology. 2006;53: 338-41.

3. Nakata B, Hirakawa YS, Chung K, Kato Y, Yamashita Y, Maeda $\mathrm{K}$, et al. Serum CA 125 level as a predictor of peritoneal dissemination in patients with gastric carcinoma. Cancer (Phila). 1998;83:2488-92.

4. Takahashi I, Maehara Y, Kusumoto T, Yoshida M, Kakeji Y, Kusumoto H, et al. Predictive value of preoperative serum sialyl Tn antigen levels in prognosis of patients with gastric cancer. Cancer (Phila). 1993;72:1836-40.

5. Tamada R, Hiramoto Y, Tsujitani S, Nozuka T, Okamura T, Masuda $\mathrm{H}$, et al. Serum CEA levels facilitate detection of recurrences of cancer in patients after gastrectomy. Jpn J Surg. $1985 ; 15: 23-9$. 
6. Koga T, Kano T, Souda K, Oka N, Inokuchi K. The clinical usefulness of preoperative CEA determination in gastric cancer. Jpn J Surg. 1987;17:342-7.

7. Maehara Y, Sugimachi K, Akagi M, Kakegawa T, Shimazu H, Tomita M. Serum carcinoembryonic antigen level increases correlate with tumor progression in patients with differentiated gastric carcinoma following noncurative resection. Cancer Res. 1990;50:3952-5.

8. Wobbes T, Thomas CM, Segers MF, Nagengast FM. Evaluation of seven tumor markers (CA 50, CA 19-9, CA 19-9 TruQuant, CA 72-4, CA 195, carcinoembryonic antigen, and tissue polypeptide antigen) in the pretreatment sera of patients with gastric carcinoma. Cancer (Phila). 1992;69:2036-41.

9. Guadagni F, Roselli M, Amato T, Cosimelli M, Perri P, Casale V, et al. CA72-4 measurement of tumor-associated glycoprotein 72 (TAG-72) as a serum marker in the management of gastric carcinoma. Cancer Res. 1992;52:1222-7.

10. Hamazoe R, Maeta M, Matsui T, Shibata S, Shiota S, Kaibara N. CA72-4 compared with carcinoembryonic antigen as a tumour marker for gastric cancer. Eur J Cancer. 1992;28:1351-4.

11. Ikeda Y, Mori M, Adachi Y, Matsushima T, Sugimachi K, Saku M. Carcinoembryonic antigen (CEA) in stage IV gastric cancer as a risk factor for liver metastasis: a univariate and multivariate analysis. J Surg Oncol. 1993;53:235-8.

12. Guadagni F, Roselli M, Cosimelli M, Ferroni P, Spila A, Casaldi $\mathrm{V}$, et al. Correlation between positive CA72-4 serum levels and lymph node involvement in patients with gastric carcinoma. Anticancer Res. 1993;13:2409-13.

13. Nakane Y, Okamura S, Akehira K, Boku T, Okusa T, Tanaka K, et al. Correlation of preoperative carcinoembryonic antigen levels and prognosis of gastric cancer patients. Cancer (Phila). 1994;73:2703-8.

14. Maehara Y, Kusumoto T, Takahashi I, Kakeji Y, Baba H, Akazawa $\mathrm{K}$, et al. Predictive value of preoperative carcinoembryonic antigen levels for the prognosis of patients with welldifferentiated gastric cancer. A multivariate analysis. Oncology. 1994;51:234-7.

15. Filella X, Fuster J, Molina R, Grau JJ, García-Valdecasas JC, Grande L, et al. TAG-72, CA19-9 and CEA as tumor markers in gastric cancer. Acta Oncol. 1994;33:747-51.

16. Victorzon M, Haglund C, Lundin J, Roberts PJ. A prognostic value of CA 19-9 but not of CEA in patients with gastric cancer. Eur J Surg Oncol. 1995;21:379-84.

17. Ikeda Y, Oomori H, Koyanagi N, Mori M, Kamakura T, Minagawa S, Tateishi H, Sugimachi K. Prognostic value of combination assays for CEA and CA19-9 in gastric cancer. Oncology. 1995;52:483-6.

18. Kodera Y, Yamamura Y, Torii A, Uesaka K, Hirai T, Yasui K, et al. The prognostic value of preoperative serum levels of CEA and CA19-9 in patients with gastric cancer. Am J Gastroenterol. 1996;91:49-53.

19. Fernandez-Fernandez L, Tejero E, Tieso A, Rabadan L, Munoz M, Santos I. Receiver operating characteristic (ROC) curve analysis of the tumor markers CEA, CA19-9 and CA72-4 in gastric cancer. Int Surg. 1996;81:400-2.

20. Spila A, Roselli M, Cosimelli M, Ferroni P, Cavaliere F, Arcuri $\mathrm{R}$, et al. Clinical utility of CA 72-4 serum marker in the staging and immediate post-surgical management of gastric cancer patients. Anticancer Res. 1996;16:2241-7.

21. Ikeda Y, Mori M, Kajiyama K, Kamakura T, Maehara Y, Haraguchi $\mathrm{Y}$, Sugimachi K. Indicative value of carcinoembryonic antigen (CEA) for liver recurrence following curative resection of stage II and III gastric cancer. Hepatogastroenterology. 1996;43:1281-7.

22. Pectasides D, Mylonakis A, Kostopoulou M, Papadopoulou M, Triantafillis D, Varthalitis J, Dimitriades M, Athanassiou A.
CEA, CA19-9, and CA50 in monitoring gastric carcinoma. Am J Clin Oncol. 1997;20:348-53.

23. Reiter W, Stieber P, Reuter C, Nagel D, Cramer C, Pahl H, et al. Prognostic value of preoperative serum levels of CEA, CA 19-9 and CA 72-4 in gastric carcinoma. Anticancer Res. 1997;17:2903-6.

24. Ikeguchi M, Katano K, Saitou H, Tsujitani S, Maeta M, Kaibara N. Pre-operative serum levels of CA72-4 in patients with gastric adenocarcinoma. Hepatogastroenterology. 1997;44:866-71.

25. Tachibana M, Takemoto Y, Nakashima Y, Kinugasa S, Kotoh T, Dhar DK, et al. Serum carcinoembryonic antigen as a prognostic factor in resectable gastric cancer. J Am Coll Surg. 1998;187: 64-8.

26. Tocchi A, Costa G, Lepre L, Liotta G, Mazzoni G, Cianetti A, et al. The role of serum and gastric juice levels of carcinoembryonic antigen, CA19-9 and CA72-4 in patients with gastric cancer. J Cancer Res Clin Oncol. 1998;124:450-5.

27. Nakajima K, Ochiai T, Suzuki T, Shimada H, Hayashi H, Yasumoto A, et al. Impact of preoperative serum carcinoembryonic antigen, CA 19-9 and alpha-fetoprotein levels in gastric cancer patients. Tumour Biol. 1998;19:464-9.

28. Marrelli D, Roviello F, De Stefano A, Farnetani M, Garosi L, Messano A, et al. Prognostic significance of CEA, CA 19-9 and CA 72-4 preoperative serum levels in gastric carcinoma. Oncology. 1999;57:55-62.

29. Kim DY, Kim HR, Shim JH, Park CS, Kim SK, Kim YJ. Significance of serum and tissue carcinoembryonic antigen for the prognosis of gastric carcinoma patients. J Surg Oncol. 2000;74:185-92.

30. Duraker N, Celik AN. The prognostic significance of preoperative serum CA 19-9 in patients with resectable gastric carcinoma: comparison with CEA. J Surg Oncol. 2001;76:266-71.

31. Marrelli D, Pinto E, De Stefano A, Farnetani M, Garosi L, Roviello F. Clinical utility of CEA, CA 19-9, and CA 72-4 in the follow-up of patients with resectable gastric cancer. Am J Surg. 2001;181:16-9.

32. Marrelli D, Pinto E, De Stefano A, de Manzoni G, Farnetani M, Garosi L, Roviello F. Preoperative positivity of serum tumor markers is a strong predictor of hematogenous recurrence of gastric cancer. J Surg Oncol. 2001;78:253-8.

33. Ishigami S, Natsugoe S, Hokita S, Che X, Tokuda K, Nakajo A, et al. Clinical importance of preoperative carcinoembryonic antigen and carbohydrate antigen 19-9 levels in gastric cancer. J Clin Gastroenterol. 2001;32:41-4.

34. Gaspar MJ, Arribas I, Coca MC, Díez-Alonso M. Prognostic value of carcinoembryonic antigen, CA19-9 and CA72-4 in gastric carcinoma. Tumour Biol. 2001;22:318-22.

35. Mattar R, Alves de Andrade CR, DiFavero GM, Gama-Rodrigues JJ, Laudanna AA. Preoperative serum levels of CA 72-4, CEA, CA 19-9, and alpha-fetoprotein in patients with gastric cancer. Rev Hosp Clin Fac Med Sao Paulo. 2002;57:89-92.

36. Lai IR, Lee WJ, Huang MT, Lin HH. Comparison of serum CA72-4, CEA, TPA, CA19-9 and CA125 levels in gastric cancer patients and correlation with recurrence. Hepatogastroenterology. 2002;49:1157-60.

37. Aloe S, D'Alessandro R, Spila A, Ferroni P, Basili S, Palmirotta R, Carlini M, Graziano F, Mancini R, Mariotti S, Cosimelli M, Roselli M, Guadagni F. Prognostic value of serum and tumor tissue CA72-4 content in gastric cancer. Int J Biol Markers. 2003;18:21-7.

38. Takahashi Y, Takeuchi T, Sakamoto J, Touge T, Mai M, Ohkura $\mathrm{H}$, et al. Tumor Marker Committee. The usefulness of CEA and/ or CA19-9 in monitoring for recurrence in gastric cancer patients: a prospective clinical study. Gastric Cancer. 2003;6:142-5.

39. Louhimo J, Kokkola A, Alfthan H, Stenman UH, Haglund C. Preoperative hCGbeta and CA $72-4$ are prognostic factors in gastric cancer. Int J Cancer. 2004;111:929-33. 
40. Mihmanli M, Dilege E, Demir U, Coskun H, Eroglu T, Uysalol MD. The use of tumor markers as predictors of prognosis in gastric cancer. Hepatogastroenterology. 2004;51:1544-7.

41. Cetin B, Atalay C, Aslan S, Babacan B, Hatipoğlu C, Akinci M, et al. Peritoneal carcinoembryonic antigen level for predicting locoregional and distant spread of gastric cancer. Surg Today. 2005;35:919-24.

42. Goral V, Yesilbagdan H, Kaplan A, Sit D. Evaluation of CA72-4 as a new tumor marker in patients with gastric cancer. Hepatogastroenterology. 2007;54:1272-5.

43. Ucar E, Semerci E, Ustun H, Yetim T, Huzmeli C, Gullu M. Prognostic value of preoperative CEA, CA19-9, CA72-4, and AFP levels in gastric cancer. Adv Ther. 2008;25:1075-84.

44. Zhang YH, Li Y, Chen C, Peng CW. Carcinoembryonic antigen level is related to tumor invasion into the serosa of the stomach: study on 166 cases and suggestion for new therapy. Hepatogastroenterology. 2009;56:1750-4.

45. Ikeguchi M, Hatada T, Yamamoto M, Miyake T, Matsunaga T, Fukumoto Y, et al. Serum interleukin-6 and -10 levels in patients with gastric cancer. Gastric Cancer. 2009;12:95-100.

46. Jung M, Jeung HC, Lee SS, Park JY, Hong S, Lee SH, et al. The clinical significance of ascitic fluid CEA in advanced gastric cancer with ascites. J Cancer Res Clin Oncol. 2010;136:517-26.

47. Dilege E, Mihmanli M, Demir U, Ozer K, Bostanci O, Kaya C, et al. Prognostic value of preoperative CEA and CA19-9 levels in resectable gastric cancer. Hepatogastroenterology. 2010;57:674-7.

48. Fan B, Xiong B. Investigation of serum tumor markers in the diagnosis of gastric cancer. Hepatogastroenterology. 2011;58: $239-45$.

49. Lukaszewicz-Zając M, Mroczko B, Gryko M, Kędra B, Szmitkowski M. Comparison between clinical significance of serum proinflammatory proteins (IL-6 and CRP) and classic tumor markers (CEA and CA 19-9) in gastric cancer. Clin Exp Med. 2011;11(2):89-96.

50. Emoto $\mathrm{S}$, Ishigami $\mathrm{H}$, Yamashita $\mathrm{H}$, Yamaguchi $\mathrm{H}$, Kaisaki $\mathrm{S}$, Kitayama J. Clinical significance of CA125 and CA72-4 in gastric cancer with peritoneal dissemination. Gastric Cancer. 2012;15:154-61.

51. Liu X, Cheng Y, Sheng W, Lu H, Xu Y, Long Z, Zhu H, Wang Y. Clinicopathologic features and prognostic factors in alpha-fetoprotein-producing gastric cancers: analysis of 104 cases. J Surg Oncol. 2010;102:249-55.

52. Inoue M, Sano T, Kuchiba A, Taniguchi H, Fukagawa T, Katai H. Long-term results of gastrectomy for alpha-fetoprotein-producing gastric cancer. Br J Surg. 2010;97:1056-61.

53. Chun H, Kwon SJ. Clinicopathological characteristics of alphafetoprotein-producing gastric cancer. J Gastric Cancer. 2011;11:23-30.

54. Liu X, Sheng W, Wang Y. An analysis of clinicopathological features and prognosis by comparing hepatoid adenocarcinoma of the stomach with AFP-producing gastric cancer. J Surg Oncol. 2012;106:299-303.

55. Bold RJ, Ota DM, Ajani JA, Mansfield PF. Peritoneal and serum tumor markers predict recurrence and survival of patients with resectable gastric cancer. Gastric Cancer. 1999;2:1-7.
56. Fujimura T, Kinami S, Ninomiya I, Kitagawa H, Fushida $S$, Nishimura G, et al. Diagnostic laparoscopy, serum CA125, and peritoneal metastasis in gastric cancer. Endoscopy. 2002;34: 569-74.

57. Hwang GI, Yoo CH, Sohn BH, Shin JH, Park YL, Kim HD, et al. Predictive value of preoperative serum CEA, CA19-9 and CA125 levels for peritoneal metastasis in patients with gastric carcinoma. Cancer Res Treat. 2004;36:178-81.

58. Takahashi I, Maehara Y, Kusumoto T, Kohnoe S, Kakeji Y, Baba $\mathrm{H}$, et al. Combined evaluation of preoperative serum sialyl-Tn antigen and carcinoembryonic antigen levels is prognostic for gastric cancer patients. Br J Cancer. 1994;69:163-6.

59. Nakagoe T, Sawai T, Tsuji T, Jibiki M, Nanashima A, Yamaguchi $\mathrm{H}$, et al. Pre-operative serum levels of sialyl Tn antigen predict liver metastasis and poor prognosis in patients with gastric cancer. Eur J Surg Oncol. 2001;27:731-9.

60. Chen XZ, Zhang WK, Yang K, Wang LL, Liu J, Wang L, et al. Correlation between serum CA724 and gastric cancer: multiple analyses based on Chinese population. Mol Biol Rep. 2012;39:9031-9.

61. Santeusanio G, Peronace L, Castagna G, De Muro G, Santi D, D'Orazio A, et al. Immunohistochemical study of carcinoembryonic antigen (CEA) in gastric tumors: correlation with preoperative serum levels, histologic type, and grade of anaplasia of the tumor. J Surg Oncol. 1988;37:13-9.

62. Staab HJ, Anderer FA, Brümmendorf T, Hornung A, Fischer R. Prognostic value of preoperative serum CEA level compared to clinical staging: II. Stomach cancer. Br J Cancer. 1982;45: 718-27.

63. Ychou M, Duffour J, Kramar A, Gourgou S, Grenier J. Clinical significance and prognostic value of CA72-4 compared with CEA and CA19-9 in patients with gastric cancer. Dis Markers. 2000;16:105-10.

64. Li Y, Yang Y, Lu M, Shen L. Predictive value of serum CEA, CA19-9 and CA72.4 in early diagnosis of recurrence after radical resection of gastric cancer. Hepatogastroenterology. 2011;58: 2166-70.

65. Choi SR, Jang JS, Lee JH, Roh MH, Kim MC, Lee WS, et al. Role of serum tumor markers in monitoring for recurrence of gastric cancer following radical gastrectomy. Dig Dis Sci. 2006;51:2081-6.

66. Yamao T, Kai S, Kazami A, Koizumi K, Handa T, Takemoto N, et al. Tumor markers CEA, CA19-9 and CA125 in monitoring of response to systemic chemotherapy in patients with advanced gastric cancer. Jpn J Clin Oncol. 1999;29:550-5.

67. Catalano V, Graziano F, Santini D, D’Emidio S, Baldelli AM, Rossi D, et al. Second-line chemotherapy for patients with advanced gastric cancer: who may benefit? $\mathrm{Br} \mathrm{J}$ Cancer. 2008;99:1402-7.

68. Kim HJ, Lee KW, Kim YJ, Oh DY, Kim JH, Im SA, et al. Chemotherapy-induced transient CEA and CA19-9 surges in patients with metastatic or recurrent gastric cancer. Acta Oncol. 2009;48:385-90. 